\title{
Comparative Study of the Efficacy of Biofeedback-Assisted Jacobson's Progressive Muscle Relaxation (JPMR) for Managing Mild/Moderate Depression
}

\author{
Swayam Prava Baral1*, Gyanendra Raghuvanshi², Abhay Paliwal ${ }^{3}$ \\ ${ }^{1}$ Central institute of Psychiatry, Ranchi, India \\ ${ }^{2}$ Department of Psychiatry, GMC, Datia, India \\ ${ }^{3}$ Department of Psychiatry, MGMMC, Indore, India \\ Email: *swayamprava123@gmail.com
}

How to cite this paper: Baral, S. P., Raghuvanshi, G., \& Paliwal, A. (2021). Comparative Study of the Efficacy of Biofeedback-Assisted Jacobson's Progressive Muscle Relaxation (JPMR) for Managing Mild/Moderate Depression. Open Journal of Depression, 10, 181-191.

https://doi.org/10.4236/ojd.2021.104012

Received: September 8, 2021

Accepted: October 22, 2021

Published: October 25, 2021

Copyright $\odot 2021$ by author(s) and Scientific Research Publishing Inc. This work is licensed under the Creative Commons Attribution International License (CC BY 4.0).

http://creativecommons.org/licenses/by/4.0/

\begin{abstract}
Biofeedback is the way of gaining greater awareness of physiological functions with a goal of self-regulation. JPMR (Jacobson's progressive muscle relaxation) causes release of tension in the skeletal muscles, neuro-muscular system is thus seen as a mediator in the relief of depressive symptoms. This study aimed to see the comparative efficacy of biofeedback-assisted JPMR, escitalopram and bimodal use of both in management in mild/moderate depression. The study was conducted at Mental Hospital, Indore, with a Sample Size of 30 [Group A 10; biofeedback, Group B 10; escitalopram, Group C 10; both]. 8 sessions of biofeedback-assisted JPMR were given to group $A$ and C. Escitalopram was given to group B and C. HAM-D and BDI were applied at baseline, 4 weeks and 8 weeks. As per BDI scale scores, biofeedback-assisted JPMR combined with escitalopram has a significantly better response than only biofeedback or only escitalopram in patients of mild to moderate depression. As per HAM-D scale scores, biofeedback-assisted JPMR combined with escitalopram has a significantly better response than only biofeedback or only escitalopram in patients of mild to moderate depression. Thus biofeedback appears to be a useful adjunctive treatment for mild to moderate depressive episode.
\end{abstract}

\section{Keywords}

Biofeedback, JPMR, Depression, Relaxation

\section{Introduction}

Biofeedback is the process of gaining greater awareness of many physiological 
functions by using instruments that provide information on the activity of those same systems (EEG, EMG, GSR, PR, TEMP, RESP), with a goal of being able to change them at will (Barlow et al., 2016). A growing body of research indicates that autonomic nervous system dysfunction in depression (Veith et al., 1994; Carney et al., 2005). The Bio-feedback method aims to counteract the effects of the Sympathetic Nervous System by promoting the action of the Parasympathetic Nervous System (Benson et al., 1974).

Most patients are trained to relax and modify their behaviour in biofeedback. Stressful events produce strong emotions, which arouse certain physiological responses. Many experts believe that these individual responses to stress can become habitual. When the body is repeatedly aroused, one or more functions may become permanently overactive. Actual damage to bodily tissues may eventually result (Lazarus \& Folkman, 1984). Biofeedback is often aimed at changing the habitual reactions to stress that can cause pain or disease. Many clinicians believe that some of their patients have forgotten how to relax. Feedback of physical responses such as skin temperature and muscle tension provides information to help patients recognize a relaxed state. The feedback signal may also act as a kind of reward for reducing tension.

In a health care environment that where cost containment and evidence-based practice are important, biofeedback provides an effective way of non-pharmacological management in neurotic disorders like mild-moderate depression that comprises the maximum percentage of depressive disorders. Moreover, it is not associated with any side effects or pain and has a long-term effect. Yucha and Montgomery's (2008) ratings are listed for the five levels of efficacy recommended by a joint task force and adopted by the Boards of Directors of the Association for Applied Psychophysiology (AAPB) and the International Society for Neuronal Regulation (ISNR) (Vaque et al., 2002). For depression, it was Level 2 (Possibly Efficacious). This study aims to demonstrate that biofeedback achieves comparable efficacy as that of pharmacological methods.

\section{Method}

\subsection{Study Objectives}

The objective is to study the efficacy of biofeedback-assisted JPMR in management of patients with mild/moderate depression and to see the comparative efficacy of biofeedback-assisted JPMR, escitalopram and bimodal use of both in management in mild/moderate depression.

\subsection{Subjects and Design}

It was a comparative longitudinal study conducted at Mental Hospital, Department of Psychiatry, MGMMC, Indore, Biofeedback Unit. Randomized sampling technique was used to recruit 30 subjects divided into Group A 10 Depression patients on biofeedback, Group B 10 Depression patients on antidepressant (escitalopram), Group C 10 Depression patients on biofeedback + antidepressant (escitalopram). 


\subsection{Inclusion Criteria}

It is Diagnosis of Depression (F32 Depressive Episode or F33 Recurrent Depressive Episode (mild and moderate), according to ICD 10 (DCR)). Patient aged between 18 - 60 yrs, either sex, who were drug naïve or drug-free for 3 months. Patients gave written informed consent.

\subsection{Exclusion Criteria}

Any co-morbid psychiatric illness, h/o substance dependence, Head injury, epilepsy, SOL, any medical co-morbidity like .hypertension, endocrinological disorder (hypothyroidism, hyperthyroidism, Cushing syndrome, diabetes mellitus,), Pregnancy and lactation, Current use of anti-hypertensive drugs, steroid hormones, growth hormone, anabolic steroids, retinoids, antipsychotics, Sedatives, immunosuppressants and immunomodulatory agents.

\subsection{Tools}

Informed Consent Form;

Socio-Demographic and Clinical Data Sheet;

General Health Questionnaire 12;

Hamilton depression rating scale;

Beck Depression Inventory;

BIOFEEDBACK MACHINE-RELAX 701;

Biofeedback workbook.

\subsection{Procedure}

Subjects were recruited from the Mental Hospital, Indore, fulfilling the inclusion and exclusion criteria. Written informed consent was taken after explaining the objectives and procedure of study in detail. Detailed physical examination was done to rule out any medical or neurological abnormality. The diagnosis of depression was made using the ICD-10. $1^{\text {st }}$ session was introductory session which involved explaining the patients' details of the study procedure. Group B and $\mathrm{C}$ patients were given escitalopram in optimum dosage. For groups A and C, Next Sessions involved 20 - 25 minutes of abdominal breathing and biofeedback guided JPMR and parameters (alpha-EEG, EMG, GSR, PR, RR, TEMPERATURE) were recorded using the biofeedback machine. Recorded audio was used for guided JPMR. Sessions were repeated once a week and continued for up to two months. Rest 6 days of the week patients had to practice the techniques at home without biofeedback. Records of changes of all the parameters of all patients (all the 3 groups) through subsequent weeks were maintained in biofeedback computer. HAM-D was applied to all patients at baseline, 4 weeks and 8 weeks.

\section{Results and Discussion}

The mean age, in years, of patients in group $A$, was $31.34 \pm 11.21$ years. The 
mean age, in years, of patients in group B, was $33.1 \pm 11.33$ years. The mean age, in years, of patients in group C, was $31.52 \pm 11.11$ years. (Table 1) Patients were more likely to have low socioeconomic status (Table 1), an urban background, and be educated up to primary school and mostly Hindu, married, and from joint families. There was no statistically significant difference among the groups in gender, habitat, education or marital status (Table 2).

The mean age of onset of depression in patient group A was $28.64 \pm 8.76$ years. The mean age of onset of depression in patient group B was $27.66 \pm 9.20$ years. The mean age of onset of depression in patient group $C$ was $29.66 \pm 9.44$ years. The mean duration of illness in patient group A was $45.48 \pm 46.08$ months. The mean duration of illness in patient group B was $53.64 \pm 45.49$ months. The mean duration of illness in patient group $C$ was $48.44 \pm 40.55$ months (Table 3 ). Most patients had precipitating factors, had no past history, had no family history and had acute onset of illness (Table 4).

Table 1. Comparison of socio-demographic profile between the groups (continuous variables).

\begin{tabular}{cccccc}
\hline \multirow{2}{*}{ Variables } & Biofeedback-assisted JPMR $(\mathrm{N}=10)$ & Escitalopram & Both & F ratio & P \\
\cline { 2 - 5 } & Mean \pm SD & Mean \pm SD & Mean \pm SD & & \\
\hline Age (in years) & $31.34 \pm 11.21$ & $33.1 \pm 11.33$ & $31.52 \pm 11.11$ & 0.312 & 0.817 \\
Total Income & $17,520.00 \pm 9006.21$ & $15,240.00 \pm 6096.00$ & $21,990.00 \pm 20,268.22$ & 2.159 & 0.094 \\
\hline
\end{tabular}

Table 2. Comparison of sociodemographic variables between the groups.

\begin{tabular}{|c|c|c|c|c|c|c|}
\hline & & $\begin{array}{l}\text { Biofeedback- } \\
\text { assisted JPMR } \\
\quad(\mathrm{N}=10)\end{array}$ & $\begin{array}{l}\text { Escitalopram } \\
\qquad(\mathrm{N}=10)\end{array}$ & $\begin{array}{l}\text { BOTH } \\
(\mathrm{N}=10)\end{array}$ & $X^{2}$ & $\mathrm{P}$ \\
\hline \multirow{2}{*}{ Gender } & Male & $6(60 \%)$ & $6(60 \%)$ & $5(50 \%)$ & \multirow{2}{*}{0.083} & \multirow{2}{*}{0.99} \\
\hline & Female & $4(40 \%)$ & $4(40 \%)$ & $5(50 \%)$ & & \\
\hline \multirow{2}{*}{ Religion } & Hindu & $7(70 \%)$ & $6(60 \%)$ & $9(90 \%)$ & \multirow{2}{*}{35.686} & \multirow{2}{*}{0.000} \\
\hline & Others & $3(30 \%)$ & $4(40 \%)$ & $1(10 \%)$ & & \\
\hline \multirow{2}{*}{ Habitat } & Rural & $4(40 \%)$ & $3(30 \%)$ & $4(40 \%)$ & \multirow{2}{*}{4.244} & \multirow{2}{*}{0.236} \\
\hline & Urban & $6(60 \%)$ & $7(70 \%)$ & $6(60 \%)$ & & \\
\hline \multirow{2}{*}{ Family type } & Joint & $6(60 \%)$ & $8(80 \%)$ & $4(40 \%)$ & \multirow{2}{*}{23.681} & \multirow{2}{*}{0.001} \\
\hline & Nuclear & $4(40 \%)$ & $2(20 \%)$ & $6(60 \%)$ & & \\
\hline \multirow{3}{*}{ Education } & Primary & $4(40 \%)$ & $4(40 \%)$ & $5(50 \%)$ & \multirow{3}{*}{35.046} & \multirow{3}{*}{0.768} \\
\hline & Secondary & $2(20 \%)$ & $4(40 \%)$ & $1(10 \%))$ & & \\
\hline & Graduate+ & $4(40 \%)$ & $2(20 \%)$ & $4(40 \%)$ & & \\
\hline \multirow{2}{*}{ Marital status } & Married & $7(70 \%)$ & $7(70 \%)$ & $5(50 \%)$ & \multirow[b]{2}{*}{7.813} & \multirow[b]{2}{*}{0.252} \\
\hline & Unmarried & $3(30 \%)$ & $3(30 \%)$ & $5(50 \%)$ & & \\
\hline
\end{tabular}


Table 3. Clinical characteristics of the depression patients (continuous variables).

\begin{tabular}{cccc}
\hline Variables & $\begin{array}{c}\text { Biofeedback- } \\
\text { assisted JPMR } \\
(\mathrm{N}=10)\end{array}$ & Escitalopram & Both \\
& Mean $\pm \mathrm{SD}$ & Mean $\pm \mathrm{SD}$ & Mean $\pm \mathrm{SD}$ \\
\hline Age of onset of illness (in years) & $28.64 \pm 8.76$ & $27.66 \pm 9.20$ & $29.66 \pm 9.44$ \\
Duration of illness (in months) & $45.48 \pm 46.08$ & $53.64 \pm 45.49$ & $48.44 \pm 40.55$ \\
\hline
\end{tabular}

Table 4. Clinical characteristics of the depression patients (categorical variables).

\begin{tabular}{ccccc}
\hline \multirow{2}{*}{ Variables } & & $\begin{array}{c}\text { Biofeedback- } \\
\text { assisted JPMR }\end{array}$ & Escitalopram & Both \\
\hline Precipitating factor & Yes & $6(60 \%)$ & $5(50 \%)$ & $6(60 \%)$ \\
& No & $4(40 \%)$ & $5(50 \%)$ & $4(40 \%)$ \\
\hline Family history & Not present & $8(80 \%)$ & $6(60 \%)$ & $8(80 \%)$ \\
& Present & $2(20 \%)$ & $4(40 \%)$ & $2(20 \%)$ \\
\hline Onset & Insidious & $3(30 \%)$ & $2(20 \%)$ & $4(40 \%)$ \\
& Acute & $7(70 \%)$ & $8(80 \%)$ & $6(60 \%)$ \\
\hline Past history & Not present & $9(90 \%)$ & $7(70 \%)$ & $6(60 \%)$ \\
& Present & $1(10 \%)$ & $3(30 \%)$ & $4(40 \%)$ \\
\hline
\end{tabular}

For group A, the HAM-D score was 11 at baseline, 7 at 1 month, and 4 at 2 months. For group B, the mean HAM-D score was 11 at baseline, 8 at 1 month, and 4 at 2 months. For group C, the mean HAM-D score was 11 at baseline, 7 at 1 month, and 3 at 2 months (Table 5). For group A, the mean BDI score was 15 at baseline, 12 at 1 month, and 10 at 2 months. For group B, the mean BDI score was 15 at baseline, 12 at 1 month, and 10 at 2 months. For group C, the mean BDI score was 15 at baseline, 12 at 1 month, and 8 at 2 months 8 (Table 6).

Significant improvements were noted in the Hamilton Depression Scale (HAM-D) and the Beck Depression Inventory (BDI) by Session 4, and further significant improvement was noted between session 4 and session 8 in patients in all groups.

The difference in BDI score (baseline vs. $8^{\text {th }}$ session) was significantly greater in group $\mathrm{C}$ (biofeedback + escitalopram) than in groups A (only biofeedback) and B (only escitalopram). The difference in BDI score (baseline vs. $8^{\text {th }}$ session) was equal for group A (only biofeedback) and group B (only escitalopram). The difference in BDI score (baseline vs. 4th session) was significantly greater in group C (biofeedback + escitalopram) than in groups A (only biofeedback) and B (only escitalopram). The difference in BDI score (baseline vs. 4th session) was significantly greater for group B (only escitalopram) than for group A (only biofeedback). The difference in BDI score (4th session vs. $8^{\text {th }}$ session) was significantly greater in group C (biofeedback + escitalopram) than in groups A (only biofeedback) and B (only escitalopram). The difference in BDI score (4th session 
vs. $8^{\text {th }}$ session) was equal for group A (only biofeedback) and group B (only escitalopram).

Therefore, according to BDI scale scores, biofeedback-assisted JPMR combined with escitalopram as a treatment modality produces a better response than

Table 5. Comparison of ham-d scores.

\begin{tabular}{|c|c|c|c|c|c|}
\hline & & \multicolumn{4}{|c|}{ Group } \\
\hline & & Biofeedback-assisted JPMR & Escitalopram & Both & Total \\
\hline \multirow{2}{*}{ HAM-D baseline } & Mean & 11.0000 & 11.1000 & 11.4000 & 11.1667 \\
\hline & Std. Deviation & 2.44949 & 2.33095 & 2.36643 & 2.30567 \\
\hline \multirow{2}{*}{ HAM-D 4th session } & Mean & 7.0000 & 8.2000 & 7.8000 & 7.6667 \\
\hline & Std. Deviation & 2.21108 & 2.25093 & 2.29976 & 2.23350 \\
\hline \multirow{2}{*}{ HAM-D 8th session } & Mean & 4.2000 & 4.4000 & 3.0000 & 3.8667 \\
\hline & Std. Deviation & 1.98886 & 2.50333 & 1.41421 & 2.04658 \\
\hline \multirow{2}{*}{ Baseline-4th session } & Mean & 4.0000 & 2.9000 & 3.6000 & 3.5000 \\
\hline & Std. Deviation & 1.63299 & 0.73786 & 0.51640 & 1.13715 \\
\hline \multirow{2}{*}{ 4th session-8th session } & Mean & 2.9000 & 4.1000 & 4.8000 & 3.9333 \\
\hline & Std. Deviation & 0.73786 & 1.44914 & 1.54919 & 1.48401 \\
\hline \multirow{2}{*}{ baseline-8th session } & Mean & 6.9000 & 7.0000 & 8.4000 & 7.4333 \\
\hline & Std. Deviation & 1.37032 & 1.88562 & 1.57762 & 1.71572 \\
\hline
\end{tabular}

\section{ANOVA Table}

\begin{tabular}{|c|c|c|c|c|c|}
\hline & & Mean Square & $\mathrm{F}$ & Sig. & Post-hoc \\
\hline \multirow{2}{*}{ HAM-D baseline ${ }^{\star}$ group } & Between Groups & 0.433 & 0.076 & 0.927 & \\
\hline & Within Groups & 5.678 & & & \\
\hline \multirow{2}{*}{ HAM-D 4th session ${ }^{\star}$ group } & Between Groups & 3.733 & 0.735 & 0.489 & \\
\hline & Within Groups & 5.081 & & & \\
\hline \multirow{2}{*}{ HAM-D 8th session * group } & Between Groups & 5.733 & 1.407 & 0.262 & \\
\hline & Within Groups & 4.074 & & & \\
\hline \multirow{3}{*}{ Baseline- 4 th session ${ }^{\star}$ group } & Between Groups & 3.100 & 2.674 & 0.087 & Both $>$ E \\
\hline & \multirow[t]{2}{*}{ Within Groups } & 1.159 & & & Both $=$ B \\
\hline & & & & & $\mathrm{B}>\mathrm{E}$ \\
\hline \multirow{3}{*}{4 th session-8th session ${ }^{*}$ group } & Between Groups & 9.233 & 5.491 & 0.010 & Both $>$ B \\
\hline & \multirow[t]{2}{*}{ Within Groups } & 1.681 & & & Both $>$ E \\
\hline & & & & & $\mathrm{E}>\mathrm{B}$ \\
\hline \multirow{3}{*}{ baseline-8th session ${ }^{\star}$ group } & Between Groups & 7.033 & 2.663 & 0.088 & Both $>$ B \\
\hline & \multirow[t]{2}{*}{ Within Groups } & 2.641 & & & Both $>$ E \\
\hline & & & & & $\mathrm{E}>\mathrm{B}$ \\
\hline
\end{tabular}


Table 6. Comparison of BDI scores.

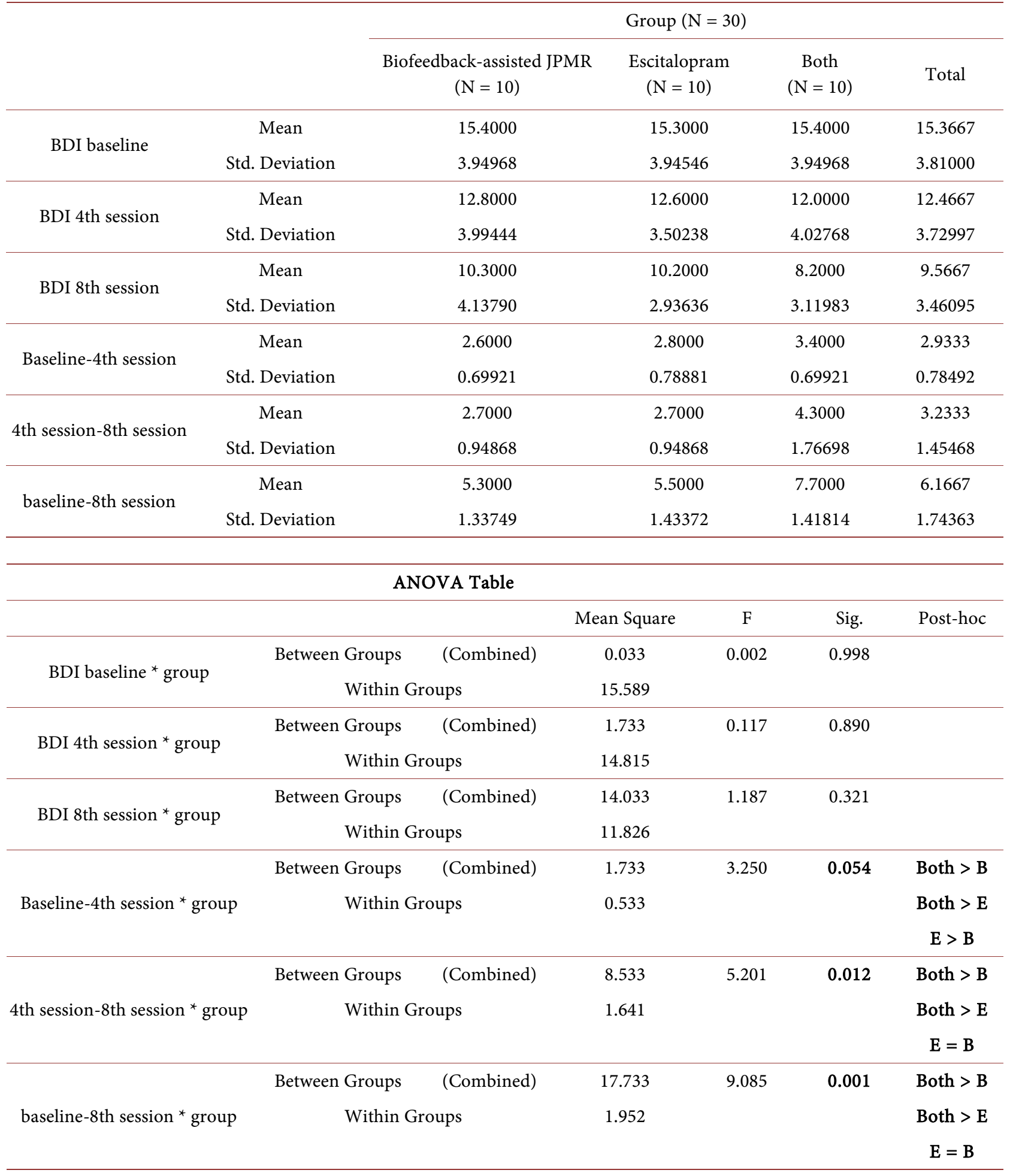

biofeedback alone or SSRIs alone (escitalopram) in patients with mild to moderate depression.

Biofeedback-assisted JPMR produces an equal response compared to escitalopram in patients with mild to moderate depression. 
The difference in HAM-D score (baseline vs. $8^{\text {th }}$ session) was greater in group $\mathrm{C}$ (biofeedback + escitalopram) than in groups A (only biofeedback) and B (only escitalopram). The difference in HAM-D score (baseline vs. $8^{\text {th }}$ session) was greater for group B (only escitalopram) than for group A (only biofeedback). The difference in HAM-D score (baseline vs. 4th session) was greater in group C (biofeedback + escitalopram) than in groups A (only biofeedback) and B (only escitalopram). The difference in HAM-D score (baseline vs. 4th session) was greater in group A (only biofeedback) than in group B (only escitalopram). The difference in HAM-D score (4th session vs. $8^{\text {th }}$ session) was significantly greater in group C (biofeedback + escitalopram) than in groups A (only biofeedback) and $B$ (only escitalopram). The difference in HAM-D score (4th session vs. $8^{\text {th }}$ session) was significantly greater for group B (only escitalopram) than for group A (only biofeedback).

Therefore, according to HAM-D scale scores, biofeedback-assisted JPMR combined with escitalopram as a treatment modality produces a better response than biofeedback alone or SSRIs alone (escitalopram) in patients with mild to moderate depression.

According to HAM-D scale scores, biofeedback-assisted JPMR produces more response than escitalopram in patients with mild to moderate depression after 1 month ( $4^{\text {th }}$ session), but produces less of a response than escitalopram between 1 to 2 months (between $4^{\text {th }}$ and $8^{\text {th }}$ session).

This finding can be explained by the fact that antidepressant action needs 2 to 3 weeks, but biofeedback-assisted JPMR acts immediately by inducing relaxation and reducing sympathetic tone.

Therefore, considering the overall improvement in symptoms for patients assessed using both HAM-D and BDI, biofeedback-assisted JPMR combined with SSRIs (escitalopram) as a treatment modality produces a better response than biofeedback alone or SSRIs alone (escitalopram) in patients with mild to moderate depression.

Only biofeedback is also a successful treatment for mild-moderate depression.

Moreover, it is not associated with any side effects or pain and has long-term effects. It improves overall relaxation for all parameters (i.e., EEG, EMG, GSR, PR, TEMP, RESP) over subsequent sessions.

The findings of this study are substantiated by the findings of previous studies. Preliminary case studies (Kumano et al., 1996; Rosenfeld, 2000) and pilot studies (Waldkoetter \& Sanders, 1997) show neurofeedback decreases depressive symptoms. One study compared biofeedback-assisted relaxation to a wait-list control on depression in chronic pain patients and improved scores on the Beck Depression Index was found (Corrado \& Gottlieb, 1999).

Physiological arousal is governed by the ANS. When the organism is under threat the SNS (Sympathetic Nervous System) increases arousal on the other hand the PNS (Parasympathetic Nervous System) restores the body to a resting state. These actions are involuntary and enable the organism to survive. When the activity of SNS is prolonged and the organism is exposed to constant threat 
the organs concerned can become fatigued. The Bio-feedback method aims to counteract the effects of SNS by promoting the action of the PNS (Basmajian, 1979).

Neuro-therapists have used EEG biofeedback when treating addiction, attention deficit hyperactivity disorder (ADHD), learning disabilities, anxiety disorders (including worry, obsessive-compulsive disorder and posttraumatic stress disorder), depression, migraines, and generalized seizures (Yucha \& Montgomery, 2008).

HRV biofeedback may be useful for reducing loss of energy, lack of motivation, sleep disturbances or any of the other neuro-vegetative features of MDD. As an inexpensive, safe, and noninvasive technique, it may prove to be a useful alternative to some medical or surgical interventions (Karavidas et al., 2007)

\section{Conclusion}

On the basis of the index study, which substantiates the earlier findings of previous studies, it can be concluded that:

Biofeedback is a useful adjunctive treatment for mild to moderate depressive episode.

Biofeedback-assisted JPMR is a successful non-pharmacological modality for the treatment of mild-moderate depression.

So, non-pharmacological methods like biofeedback should be added to the pharmacological management of mild-moderate depression.

\section{Advantages}

This is the only study of its kind that compared the response three groups (only biofeedback, only escitalopram and both).

Previous studies had conducted fewer sessions of biofeedback.

\section{Limitations}

Sample size could have been larger.

\section{Future Directions}

Further studies with larger sample size and more sessions of biofeedback-assisted JPMR should be conducted in patients with depression as well as other psychosomatic illnesses.

Biofeedback is applicable not only for people suffering from any psychological or physiological disorders but also applied to normal healthy individuals as Peak Achievement Training for improving attention and concentration. So the further studies should be done in this regard.

\section{Declarations}

\section{Acknowledgements}

Authors wish to thank Department of Psychiatry MGM Medical College, Indore. 


\section{Ethical Approval}

The study was approved by Institutional Ethical Committee, MGMMC, Indore.

\section{Authors Contribution}

Dr. S. P. Baral and Dr. G. Raghuvanshi collected the data and analysed the date and compiled it. Dr. A. Paliwal guided the project.

\section{Consent}

Consent for publication was obtained from each author and the institution.

\section{Conflicts of Interest}

There are no conflicts of interest.

\section{References}

Barlow, D. H., Durand, V. M., \& Hofmann, S. G. (2016). Abnormal Psychology: An Integrative Approach. Cengage Learning.

Basmajian, J. V. (1979). Biofeedback: Principles and Practice for Clinicians. Williams \& Wilkins.

Benson, H., Beary, J. F., \& Carol, M. P. (1974). The Relaxation Response. Psychiatry, 37, 37-46. https://doi.org/10.1080/00332747.1974.11023785

Carney, R. M., Freedland, K. E., \& Veith, R. C. (2005). Depression, the Autonomic Nervous System, and Coronary Heart Disease. Psychosomatic Medicine, 67, S29-S33. https://doi.org/10.1097/01.psy.0000162254.61556.d5

Corrado, P., \& Gottlieb, H. (1999). The Effect of Biofeedback and Relaxation Training on Depression in Chronic Pain Patients. American Journal of Pain Management, 9, 18-21.

Karavidas, M. K., Lehrer, P. M., Vaschillo, E. G., Vaschillo, B., Marin, H., Buyske, S. et al. (2007). Preliminary Results of an Open-Label Study of Heart Rate Variability Biofeedback for the Treatment of Major Depression. Applied Psychophysiology and Biofeedback, 32, 19-30. https://doi.org/10.1007/s10484-006-9029-Z

Kumano, H., Horie, H., Shidara, T., Kuboki, T., Suematsu, H., \& Yasushi, M. (1996). Treatment of a Depressive Disorder Patient with EEG-Driven Photic Stimulation. Biofeedback and Self-Regulation, 21, 323-334. https://doi.org/10.1007/BF02214432

Lazarus, R. S., \& Folkman, S. (1984). Stress, Appraisal, and Coping. Springer Publishing Company.

Rosenfeld, J. P. (2000). An EEG Biofeedback Protocol for Affective Disorders. Clinical Electroencephalography, 31, 7-12. https://doi.org/10.1177/155005940003100106

Vaque, T. J. L., Hammond, D. C., Trudeau, D., Monastra, V., Perry, J., Lehrer, P., Sherman, R. et al. (2002). Template for Developing Guidelines for the Evaluation of the Clinical Efficacy of Psychophysiological Interventions. Journal of Neurotherapy, 6, 11-23. https://doi.org/10.1300/J184v06n04_03

Veith, R. C., Lewis, N., Linares, O. A., Barnes, R. F., Raskind, M. A., Villacres, E. C., Pascualy, M. et al. (1994). Sympathetic Nervous System Activity in Major Depression: Basal and Desipramine-Induced Alterations in Plasma Norepinephrine Kinetics. Archives of General Psychiatry, 51, 411-422.

https://doi.org/10.1001/archpsyc.1994.03950050071008

Waldkoetter, R. O., \& Sanders, G. O. (1997). Auditory Brainwave Stimulation in Treating 
Alcoholic Depression. Perceptual and Motor Skills, 84, 226.

https://doi.org/10.2466/pms.1997.84.1.226

Yucha, C., \& Montgomery, D. (2008). Evidence-Based Practice in Biofeedback and Neurofeedback. AAPB. 